\title{
A Rare Case of Herpes Zoster in an Adult Patient Recovered From Symptomatic Reinfection of COVID-19
}

\author{
Binita Ghosh ${ }^{1}$, Rohan A. Gajjar ${ }^{2}$, Vaishnavi K. Modi ${ }^{3}$, Dhigishaba M. Jadeja ${ }^{4}$
}

1. Internal Medicine, Burdwan Medical College, Burdwan, IND 2. Internal Medicine, BJ Medical College, Ahmedabad, IND 3. Internal Medicine, Baroda Medical College, Vadodara, IND 4. Internal Medicine, Gujarat Adani Institute of Medical Sciences, Bhuj, IND

Corresponding author: Dhigishaba M. Jadeja, dhigishabajadeja@gmail.com

\begin{abstract}
In coronavirus disease 2019 (COVID-19) patients, various dermatological conditions have been observed. Varicella zoster virus (VZV) and herpes simplex virus must be ruled out before considering vesicular exanthems linked to COVID-19. The immunological status of the host has an impact on the natural history of herpes zoster (HZ). Age is a major risk factor for most of the cases of HZ. Reactivation of VZV can be triggered by iatrogenic immunosuppression or disease-related immunocompromised state or age-related immunosenescence. Rarely, dermatological symptoms have been reported in recovered COVID-19 patients. We hereby present a rare case of $\mathrm{HZ}$ in a recovered patient from symptomatic reinfection of COVID-19.
\end{abstract}

Categories: Internal Medicine

Keywords: herpes zoster, covid-19, varicella zoster, sars-cov-2, adult

\section{Introduction}

As of June 8, 2021, the severe acute respiratory syndrome coronavirus 2 (SARS-CoV-2), has affected $29,762,793$ people and caused 383,490 deaths, with a case fatality rate of $1.28 \%$ in India, which was $1.60 \%$ as of September 22, 2020 [1]. The present coronavirus disease 2019 (COVID-19) is a worldwide multisystemic disorder with devastating medical and social implications [2-4]. While COVID-19 related cutaneous symptoms are becoming more common, their precise incidence is yet to be determined, their pathophysiological processes are still unclear, and the involvement of SARS-CoV-2 in their pathogenesis, whether direct or indirect, is still disputed. Herpes zoster $(\mathrm{HZ})$ is one of the frequently reported cutaneous conditions in COVID-19 positive patients. There are only a few cases of $\mathrm{HZ}$ reported in the literature following recovery from COVID-19. Prolonged dermatological symptoms in recovered COVID-19 patients are uncommon. We hereby, present a rare case of $\mathrm{HZ}$ in a recovered adult patient from symptomatic reinfection of COVID-19.

Review began 06/22/2021 Review ended 06/28/2021 Published 07/08/2021

\section{() Copyright 2021}

Ghosh et al. This is an open access article distributed under the terms of the Creative Commons Attribution License CC-BY 4.0., which permits unrestricted use, distribution, and reproduction in any medium, provided the original author and source are credited.

\section{Case Presentation}

A 26-year-old male working as a resident medical officer (RMO) at the tertiary care center presented to the dermatology clinic with the chief complaint of painful blisters with ulcerations and mild itching over thoraco-abdomen corresponding to right T11-12 dermatome. His past medical history was unremarkable except for positive SARS-CoV-2 infection diagnosed through nasal swab reverse transcriptase-polymerase chain reaction (RT-PCR) in May 2020. At that time, he was treated with hydroxychloroquine, azithromycin, and with other supportive treatments. He successfully recovered after one week of treatment. He was deemed negative by the resolution of his COVID-19 symptoms. He again developed symptomatic reinfection of COVID-19 on April 21, 2021, diagnosed through RT-PCR. Although, gene sequencing was not performed. At this time, he was treated with favipiravir, ivermectin, azithromycin, aspirin, vitamin $\mathrm{C}$, and vitamin D. He recovered after two weeks of COVID-19 diagnosis. On May 15, 2021, typical symptoms of HZ started to develop such as vesicles with surrounding erythema, painful blisters with ulcerations, mild itching, and unilaterally characterized to the thoraco-abdomen region corresponding to right T11-12 dermatome resulting in a clinical diagnosis of HZ. Furthermore, he had a history of VZV infection in his childhood. At the time of the appearance of HZ-specific symptoms, his RT-PCR for SARS-CoV-2 came negative. Furthermore, he was tested for human immunodeficiency virus (HIV) antibodies in July 2020, which came non-reactive. Laboratory blood markers such as total white blood cells (WBC) and absolute lymphocyte count (ALC) were within the normal range (Figure 1). 


\section{Cureus}

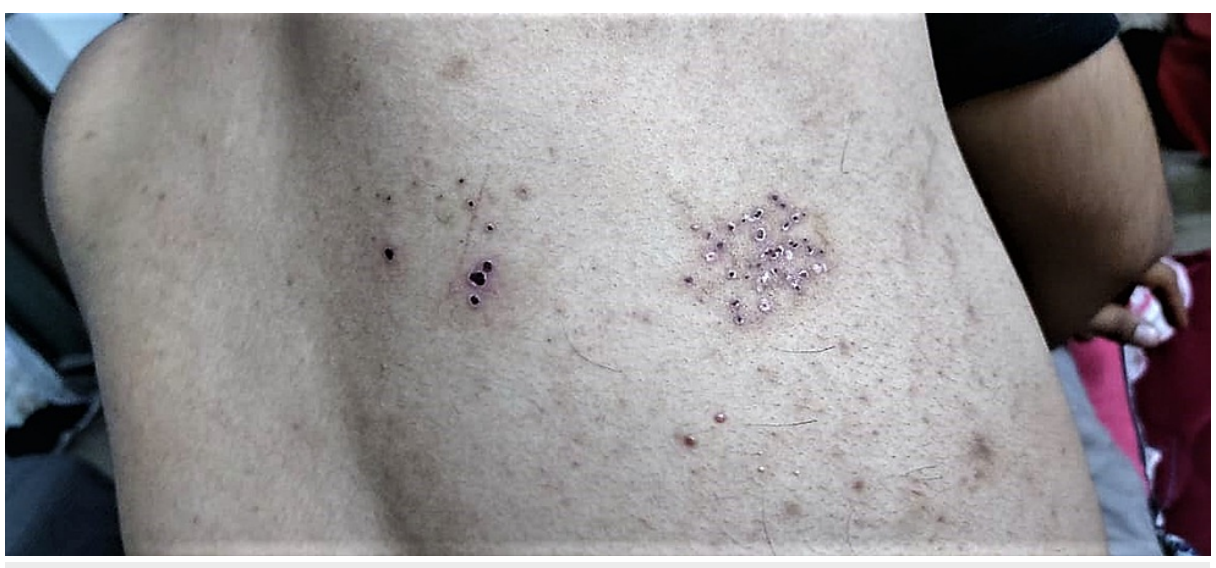

FIGURE 1: Skin lesion in recovered COVID-19 adult patient.

COVID-19, coronavirus disease 2019

He was successfully treated with acyclovir $800 \mathrm{mg}$ five times a day orally with other supportive symptomatic treatments for eight days. On follow-up evaluation, cutaneous manifestation has resolved and was continued on supportive treatment with multivitamins.

\section{Discussion}

COVID-19 disease involves multiple organ systems in the human body causing respiratory, cardiovascular, renal, neurological, hematological, olfactory, gustatory, ocular, cutaneous, and gastrointestinal manifestations [5-6]. Contemporary studies revealed different dermatological symptoms in patients with COVID-19 including maculopapular erythematous rash, vesicles, urticaria, chilblains-like lesions (COVID toes), vasculopathic lesions like petechiae, livedo reticularis, cyanosis in finger and toes, skin bullae, and dry gangrene [7]. Although most of the cutaneous manifestations of COVID-19 have been attributed to microthromboses, lymphocytic vasculitis, or Langerhans cell activation by the SARS-CoV-2 [8]. A few studies described an increase in HZ co-infection causing skin lesions during the COVID-19 pandemic [9]. HZ is caused by the reactivation of latent varicella virus in dorsal root ganglia years after primary varicella infection. The reactivated virus travels along sensory axons to infect epithelial cells causing vesicular skin rash within the dermatome innervated by the particular sensory nerve. The reactivation of the VZV is considered to be a result of a decline in VZV-specific cell-mediated immunity most commonly due to aging or other causes of immunosuppression. In immunocompetent adults, $\mathrm{HZ}$ is usually seen in the age group above 50 years [9]. Similarly, the majority of the cases of HZ developed in patients with COVID-19 were reported in patients aged above 50 years [9]. However, Nofal et al. described four immunocompetent patients developing HZ ophthalmicus in the age group of 7-42 years during active COVID-19 infection [10]. Most of the cases of HZ in COVID-19 patients developed skin lesions in a period ranging from two days before to seven days after onset of COVID-19 symptoms [10-13]. Studies have reported the development of HZ following recovery of COVID-19 [7, 14].

Reactivation of HZ in COVID-19 patients can be explained by the immune alteration apparent in such patients. A decrease in total lymphocytes, a cluster of differentiation (CD4+) T cells, CD8+ T cells, B cells, and natural killer (NK) cells are observed in COVID-19 patients [9]. Functional exhaustion of CD8+ T cells and NK cells with increased expression of natural killer cell receptor (NKG2A) causing decreased antiviral immunity is also evident in the early stages of SARS-CoV-2 infection [15].

We report a case of $\mathrm{HZ}$ in a 26-year-old male working as RMO two weeks after recovery from COVID-19. He presented with a painful vesicular rash in T11-T12 dermatomes. Unlike most of the other cases reported, our patient developed symptoms of $\mathrm{HZ}$ at a relatively younger age and few weeks after recovery from the symptomatic reinfection of COVID-19. Literature is now buzzing with symptomatic reinfection of COVID19 [16]. His recovery was confirmed with a negative RT-PCR test for symptomatic reinfection of SARS-CoV-2, lack of immunoglobulin (IgM), and presence of IgG antibodies against SARS-CoV-2. WBC count was found to be normal at the time of onset of HZ. Various studies have reported psychological stress as a risk factor for the development of HZ [17-19]. In the present case, stresses related to his hectic in-hospital COVID-19 emergency duty, post-COVID stress disorder may have served as a mechanism for the development of HZ following recovery from COVID-19. Furthermore, due to mandated social distance and a lack of viable therapies during the COVID-19 pandemic, telemedicine has proven to be the safest interaction method between patients and physicians [20]. Many skin conditions can be diagnosed and prevented through telemedicine during such pandemics.

\section{Conclusions}


The majority of the cases of HZ developed in patients with COVID-19 were reported in patients aged above 50 years. To date, few cases reported dermatological manifestation following recovery from COVID-19. To our knowledge, this is the first case of $\mathrm{HZ}$ developed in an adult patient following recovery from COVID-19. Nevertheless, the number of total lymphocytes, T cells, B cells, and NK cells increased upon recovery from the disease. Further studies are required to explore the factors that predispose patients to the development of HZ following recovery from COVID-19 particularly in patients who are at developing post-COVID stress disorder.

\section{Additional Information \\ Disclosures}

Human subjects: Consent was obtained or waived by all participants in this study. Conflicts of interest: In compliance with the ICMJE uniform disclosure form, all authors declare the following: Payment/services info: All authors have declared that no financial support was received from any organization for the submitted work. Financial relationships: All authors have declared that they have no financial relationships at present or within the previous three years with any organizations that might have an interest in the submitted work. Other relationships: All authors have declared that there are no other relationships or activities that could appear to have influenced the submitted work.

\section{References}

1. Ansari AA, Desai HD, Sharma K, Jadeja DM, Patel R, Patel Y, Desai HM: Prevalence and cross states comparison of case fatality rate and recovery rate of COVID 19/SARS-COV-2 in India. J Family Med Prim Care. 2021, 10:475-480.10.4103/jfmpc.jfmpc_1088_20

2. Desai HD, Sharma K, Jadeja DM, Desai HM, Moliya P: COVID-19 pandemic induced stress cardiomyopathy: a literature review. Int J Cardiol Heart Vasc. 2020, 31:100628. 10.1016/j.ijcha.2020.100628

3. Desai HD, Jadeja DM, Sharma K: Takotsubo syndrome a rare entity in patients with COVID-19: an updated review of case-reports and case-series. Int J Cardiol Heart Vasc. 2020, 29:100604.

10.1016/j.ijcha.2020.100604

4. Singhavi R, Sharma K, Desai HD, Patel R, Jadeja D: A case of hemolytic anemia with acute myocarditis and cardiogenic shock: a rare presentation of COVID-19. Cureus. 2020, 12:e10657. 10.7759/cureus.10657

5. Desai HD, Sharma K, Parikh A, et al.: Predictors of mortality amongst tocilizumab administered COVID-19 Asian Indians: a predictive study from a tertiary care centre. Cureus. 2021, 13:e13116. 10.7759/cureus.13116

6. Sharma K, Desai HD, Patoliya JV, Jadeja DM, Gadhiya D: Takotsubo syndrome a rare entity in COVID-19: a systemic review-focus on biomarkers, imaging, treatment, and outcome. SN Compr Clin Med. 2021, 3:62-72. 10.1007/s42399-021-00743-4

7. Desai HD, Sharma K, Patoliya JV, Ahadov E, Patel NN: A rare case of Varicella-Zoster virus reactivation following recovery from COVID-19. Cureus. 2021, 13:e12423. 10.7759/cureus.12423

8. Sachdeva M, Gianotti R, Shah M, et al.: Cutaneous manifestations of COVID-19: report of three cases and a review of literature. J Dermatol Sci. 2020, 98:75-81. 10.1016/j.jdermsci.2020.04.011

9. Diez-Domingo J, Parikh R, Bhavsar AB, Cisneros E, McCormick N, Lecrenier N: Can COVID-19 increase the risk of herpes zoster? A narrative review. Dermatol Ther (Heidelb). 2021, 1-8. 10.1007/s13555-021-00549-1

10. Nofal A, Fawzy MM, Sharaf El Deen SM, El-Hawary EE: Herpes zoster ophthalmicus in COVID-19 patients. Int J Dermatol. 2020, 59:1545-1546. 10.1111/ijd.15240

11. Tartari F, Spadotto A, Zengarini C, et al.: Herpes zoster in COVID-19-positive patients. Int J Dermatol. 2020, 59:1028-1029. 10.1111/ijd.15001

12. Saati A, Al-Husayni F, Malibari AA, Bogari AA, Alharbi M: Herpes zoster co-infection in an immunocompetent patient with COVID-19. Cureus. 2020, 12:e8998. 10.7759/cureus.8998

13. Shors AR: Herpes zoster and severe acute herpetic neuralgia as a complication of COVID-19 infection . JAAD Case Rep. 2020, 6:656-657. 10.1016/j.jdcr.2020.05.012

14. Brambilla L, Maronese CA, Tourlaki A, Veraldi S: Herpes zoster following COVID-19: a report of three cases . Eur J Dermatol. 2020, 30:754-756. 10.1684/ejd.2020.3924

15. Zheng M, Gao Y, Wang G, et al.: Functional exhaustion of antiviral lymphocytes in COVID-19 patients . Cell Mol Immunol. 2020, 17:533-535. 10.1038/s41423-020-0402-2

16. Vora T, Vora P, Vora F, Sharma K, Desai HD: Symptomatic reinfection with COVID-19: a first from Western India. J Family Med Prim Care. 2021, 10:1496-1498. 10.4103/jfmpc.jfmpc_2002_20

17. Schmader K, Studenski S, MacMillan J, Grufferman S, Cohen HJ: Are stressful life events risk factors for herpes zoster?. J Am Geriatr Soc. 1990, 38:1188-1194. 10.1111/j.1532-5415.1990.tb01497.x

18. Schmader K, George LK, Burchett BM, Pieper CF: Racial and psychosocial risk factors for herpes zoster in the elderly. J Infect Dis. 1998, 178:S67-S70.

19. Schmader K, George LK, Burchett BM, Hamilton JD, Pieper CF: Race and stress in the incidence of herpes zoster in older adults. J Am Geriatr Soc. 1998, 46:973-977. 10.1111/j.1532-5415.1998.tb02751.x

20. Sharma K, Desai HD: Role of self-measured home blood pressure monitoring (HBPM) and effectiveness of telemedicine during the era of COVID-19 pandemic. SN Compr Clin Med. 2021, 3:1071-1073. 10.1007/s42399-021-00852-0 